Article

\title{
Membrane Technology in Catalytic Carbonylation Reactions
}

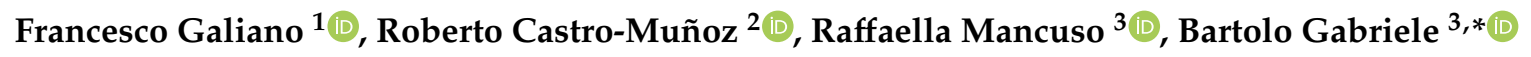 \\ and Alberto Figoli $1, *$ (i) \\ 1 Institute on Membrane Technology (ITM-CNR), Via P. Bucci 17/c, 87036 Arcavacata di Rende (CS), Italy \\ 2 Tecnológico de Monterrey, Campus Toluca, Avenida Eduardo Monroy Cárdenas 2000 San Antonio \\ Buenavista, 50110 Toluca de Lerdo, Mexico \\ 3 Laboratory of Industrial and Synthetic Organic Chemistry (LISOC), Department of Chemistry and Chemical \\ Technologies, University of Calabria, 87036 Arcavacata di Rende (CS), Italy \\ * Correspondence: bartolo.gabriele@unical.it (B.G.); a.figoli@itm.cnr.it (A.F.); \\ Tel.: +39-0984-492815 (B.G.); +39-0984-492027 (A.F.)
}

Received: 22 June 2019; Accepted: 18 July 2019; Published: 19 July 2019

\begin{abstract}
In this review, the recent achievements on the use of membrane technologies in catalytic carbonylation reactions are described. The review starts with a general introduction on the use and function of membranes in assisting catalytic chemical reactions with a particular emphasis on the most widespread applications including esterification, oxidation and hydrogenation reactions. An independent paragraph will be then devoted to the state of the art of membranes in carbonylation reactions for the synthesis of dimethyl carbonate (DMC). Finally, the application of a specific membrane process, such as pervaporation, for the separation/purification of products deriving from carbonylation reactions will be presented.
\end{abstract}

Keywords: carbonylation; dimethyl carbonate; membranes; membrane reactors; pervaporation

\section{Membranes in Catalytic Reactions}

Membranes technology is widely used in a broad range of applications. Based on their structure and function, they may operate in several processes, which include separation, purification, concentration and fractionation. Membranes act as selective barriers able to discriminate the permeation of target molecules while retaining others for achieving the separation [1]. Pressure-driven membrane processes such as microfiltration (MF), ultrafiltration (UF) and nanofiltration (NF) rely on their separation ability on the physical rejection of the species to be separated on the basis of membrane pore size and charge (in the case of NF). The pore size of the membranes can range from $1 \mu \mathrm{m}$, for MF membranes, to $2 \mathrm{~nm}$ in the case of NF membranes. Dense membranes are operated, on the contrary, in other applications such as pervaporation (PV) and gas separation where the separation of target molecules occurs on the basis of their solubility and diffusivity within the membrane material [2]. Besides these more traditional and well-known applications, suitably functionalized membranes can be employed in other important and innovative fields. For example, the possibility to combine the separation properties of synthetic membranes with chemical transformations operated by specific catalysts, has opened up new perspectives in the field of catalysis. First attempts where homogeneous catalysis was combined with membranes date back to the works of Bayer et al. in 1975 [3,4]. At that time, the main problem encountered was the insufficient retention of the catalysts in the reaction media due to the large molecular weight cut-off (MWCO) of the membranes. From that time on, many efforts have been devoted to the development of more and more reliable and efficient membranes to be used for improving the yield and the efficiency of catalytic reactions. Catalysis currently represents 
$90 \%$ of chemical production processes and $20 \%$ of industrial production processes of chemicals [5]. In membrane reactors (MRs) the membrane can have multiple roles: (1) Support function (Figure 1a,b); (2) segregation function (Figure 1c) and (3) catalytic function (Figure 1d). As supporting material, the membrane can be used for the physical immobilization or the chemical anchoring of a catalyst on the membrane surface (Figure 1a) or within its matrix (Figure 1b).

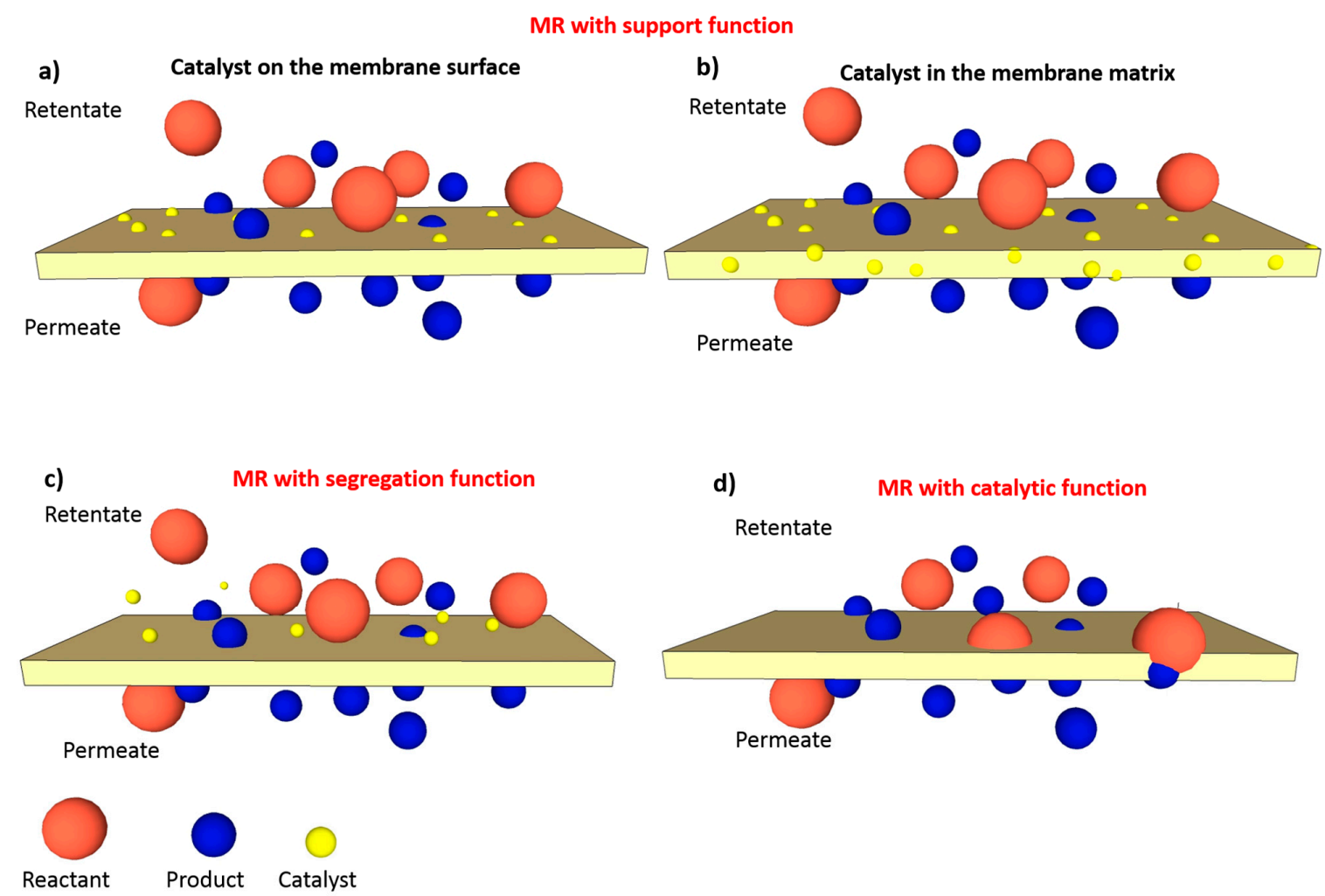

Figure 1. Possible functions of a membrane in a membrane reactor: Membrane as a catalyst support located on the surface (a) or within the matrix (b); membrane with segregation function (c) and membrane with catalytic function $(\mathbf{d})$.

Regarding the segregation function (Figure 1c) the membrane can separate the products from the reactants, can retain the catalyst in the reaction medium and can control the addition of one or more reactants [6].

In other cases, the membrane itself has catalytic properties (Figure 1d). Cation-exchange membranes or palladium membranes, for instance, do not need the addition of any catalyst to perform the conversion reaction being themselves already catalytic. In most of the cases, the membrane contributes to the overall process in more than one function at the same time.

In all the cases above reported the membrane always has a separation function. However, in particular applications, such as contactor MRs, the membrane (usually hydrophobic with small pores of 50-100 nm) has the only function of acting just as a support for the catalyst without directly performing a selective separation but just providing a contact area between the phases (usually a liquid and a gas phases) [7].

Advantages of MRs are multiple and make this technology attractive for its efficiency and from the economical point of view. Many of the benefits derive from the segregation capacity of the membrane. The membrane isolates, in fact, the reactants from the products of the reaction. This allows us to shift the reaction equilibrium increasing the product yield (this type of MR is also known as extractor MR). Moreover, the continuous product removal can avoid the generation of undesired side reactions [8]. The product obtained has generally a high purity and the downstream processing is much easier [9]. Moreover, the catalysts are immobilized within the membrane with the possibility to recycle and reuse 
them several times avoiding their isolation and recovery from liquid media. Membrane separation occurs generally at mild temperatures preserving the integrity of species sensitive to the temperature. The membrane can also dose the addition of reactants, which are inclined to react in successive reactions keeping their level low (this type of MR is known also as distributor MR) [10].

Besides the undoubtable benefits that MRs exhibit, a series of drawbacks have to be carefully taken in consideration such as the thermal, chemical and mechanical stability of the membranes (above all for the polymeric based ones), the possible leaching of the catalyst in time and the manufacturing cost of the membrane module.

Metallic and inorganic membranes were the first membranes used in MRs [11]. They present superior mechanical, thermal and chemical stability in comparison to polymeric materials and are the preferred choice for the reactions conducted at very high temperatures (such as hydrogenation and dehydrogenation). However, their exploitation at industrial level is still hindered by their high cost, low permeability and difficulties in their preparation without defects. These membranes are generally produced by the sol-gel method, hydrothermal crystallization, processing of submicron powders or chemical vapor deposition $[12,13]$.

Polymeric based membranes are certainly the most studied and investigated membranes in MRs. Their production processes, mainly by phase inversion techniques (solvent evaporation, non-solvent precipitation, thermal precipitation and vapor induced phase separation), are very well known and simple methods employed for their preparation. Polymeric materials, moreover, offer tunable properties due also to the presence of a high variety of polymers available. MF, UF, NF, reverse osmosis and PV membranes have been used and successfully applied in MRs. Polymeric membranes, however, may suffer of fouling and poor chemical and mechanical resistance.

The incorporation of a catalyst in a polymeric membrane can occur following two different paths: In case of existing membranes, the catalyst is added through the chemical functionalization of the membrane or immobilization on its surface or within its structure (such as adsorption) [14], alternatively the catalyst can be preliminary dispersed in the polymer solution that will be used for the preparation of the membrane [15]. The addition of a catalyst into a polymer membrane can alter and modify its properties in terms of wettability, pore size, morphology and mechanical resistance. In turn, the type of polymer and the preparation procedure can have a strong influence on the catalyst activity and availability. Therefore, the choice of the polymer, of the catalyst and of the membrane preparation method and conditions are fundamental aspects that have to be deeply considered in MRs. In Figure 2 the main features of MRs are schematically reported. 


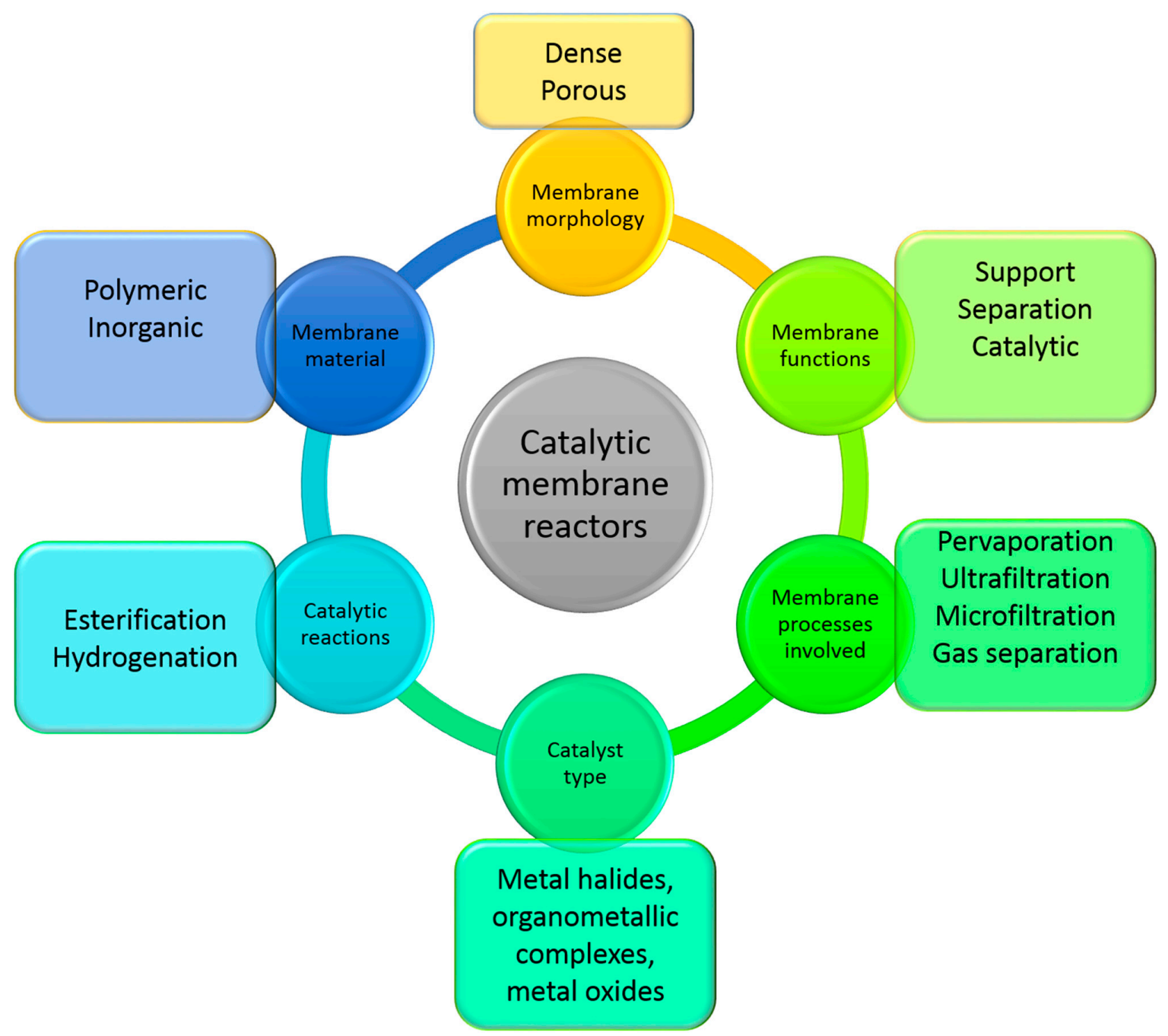

Figure 2. Catalytic membrane reactors main features.

In the following sections some of the most common catalytic reactions, in both gas and liquid phases, that can be performed and assisted by MRs, are reported.

\subsection{Esterification}

Esters may be produced through an esterification reaction by reacting a carboxylic acid with an alcohol in the presence of a mineral acid. Heterogeneous acid catalysts are generally the most employed for this type of conversion respect of the homogenous ones [16] since they give the possibility to operate at lower temperatures. However, in esterification reactions, in order to overcome the thermodynamic equilibrium, it is necessary to add an excess of alcohol or carboxylic acid for shifting the equilibrium towards the formation of the products. In alternative, it is possible to constantly remove from the reaction medium one of the esterification products (water or the ester) and, thus, improving the yield. Esterification assisted by the PV process, in this regard, can greatly support these type of reactions [17-19]. Through the use of organophilic or hydrophilic dense membranes, in fact, it is possible to constantly remove the ester or the water increasing considerably the reaction conversion.

Souza Figueiredo et al. [20], for instance, studied, in PV, the esterification reaction of acetic acid and ethanol for the production of ethyl acetate considering two different approaches: (1) Reaction and separation conducted in two different and separated steps; (2) reaction and separation occurring in one single step. Amberlyst 35 and 15 were used as catalysts. In the first approach, a Pervap 1000 commercial membrane was used for achieving the separation and the catalyst was dissolved in the 
feed solution constituted by the alcohol and the carboxylic acid. In the second approach, the catalyst was directly embedded in a polyvinyl alcohol (PVA) matrix used as coating material for the Pervap100 membrane. Both membranes (Pervap 1000 and Pervap 1000 + PVA + catalyst) displayed a hydrophilic character, which made them ideal for the removal of water produced during the esterification reaction. The catalytic membrane presented an increase up to $60 \%$ on ester yield in $8 \mathrm{~h}$ in comparison to the commercial membrane not containing any catalyst, keeping, at the same time, its transport properties (flux of $40 \mathrm{~g} / \mathrm{m}^{2} \mathrm{~h}$ and an enrichment factor of 17). Therefore, the possibility to directly operate the conversion and the separation in one single step (directly within the membrane) was found to be more advantageous and efficient than running the reaction in two different and separated steps.

Zhang et al. [21] reported the application of catalytic membranes in a PV-assisted esterification between acetic acid and $n$-butanol using a three layer membrane made of a porous catalytic top layer, a middle PVA selective dense layer and polyethersulfone (PES) support. Ion-exchange resin of cross-linked styrene-divinyl benzene was used as a catalyst. In batch conditions, pure catalyst beads (not embedded into the membrane) exhibited the best conversion performance (about 68\%) while the activity of catalysts loaded into the membrane was just slightly lower (about 65\%). The membranes tested in the PV reactor were able to combine the conversion reaction together with the separation of water (by-product of the esterification reaction) reaching an acetic acid conversion of $94.7 \%$, which was about $27 \%$ higher in respect to the reaction equilibrium conversion. The removal of water from the reaction medium allowed us, in fact, to shift the equilibrium conversion enhancing the formation of the ester.

Porous UF polyethersulfone (PES) catalytic membranes were realized by El-Zanati and Abdallah [22] for the esterification between ethyl hexanoic acid with ethanol for the production of ethyl hexanoic ester. Once the PES membrane was produced by a phase inversion technique, the catalyst, consisting in sulfonic groups, was grafted on the membrane surface following a three-step procedure. The porous architecture of the membrane guaranteed a high contact surface between the reactants and the catalytic groups of the membrane reducing, at the same, the mass transfer resistance of the material. At the following operating conditions: Temperature of $30^{\circ} \mathrm{C}$, molar ratio of ethanol: Carboxylic acid of $5: 1$ and an internal membrane pore surface of $252,450 \mathrm{~cm}^{2}$, the maximum conversion rate of $99.7 \%$ was obtained.

\subsection{Hydrogenation}

Membranes can offer several advantages in hydrogenation reactions carried out in liquid phase. These types of reactions, in fact, are usually performed at high pressures in order to improve the weak solubility of $\mathrm{H}_{2}$ in most of the organic solvents. Catalytic membranes, on the contrary, are able to provide a three-phase contact avoiding the use of high pressure [23]. Moreover, respect to the traditional fixed bed reactors, where the catalysts are packed in, catalytic membranes generally show higher selectivity by reducing the transport process between empty spaces [24].

The hydrogenation of furfural to furfuryl alcohol is a relevant industrial conversion for the production of resins. In recent work, Bagnato et al. [25] developed a novel catalytic membrane through the modification of a commercial PES membrane surface with acrylic acid and Ru nanoparticles. When applied for the hydrogenation of furfural, the membranes presented a conversion of $26 \%$ after $30 \mathrm{~min}$, a selectivity $>99 \%$ and a turnover frequency (TOF) of $48,000 \mathrm{~h}^{-1}$, which was the highest value obtained when compared with literature data. The catalytic membrane, moreover, allowed us to operate the conversion under mild conditions with a temperature of $70^{\circ} \mathrm{C}$ and a pressure of $7 \mathrm{bar}$.

A series of partial hydrogenation reactions 1,5-cyclooctadiene to cyclooctene, 1-octyne to octene, phenylacetylene to styrene and geraniol to citronellol was studied by Schmidt et al. [24] using a porous polyacrylic acid (PAA) membrane and immobilized Pd particles as catalysts. The selectivity of conversion reactions operated by the MR was compared to the fixed bed reactor (FBR) and slurry reactor (SR) where no membranes were used. The MR showed in all cases better results in terms of selectivity in comparison to the other two approaches considered. In particular, for phenylacetylene 
and 1,5-cyclooctadiene a selectivity of 90 was obtained, while for 1-octyne and geraniol a selectivity of 93 and 50, respectively, were achieved. It was found that the higher the $k_{1}$ rate constant (of the first partial hydrogenation reaction) with respect to the $k_{2}$ rate constant (related to the second hydrogenation reaction), the lower the resistance in mass transfer for the reaction. In this case, the selectivity for MR, FBR and SR was similar (such as the case of 1-octyne). On the contrary, the effect of mass transfer was more pronounced for the hydrogenation of geraniol because the two rate constants $\left(k_{1}\right.$ and $\left.k_{2}\right)$ have almost equal values. Fort these types of reactions the MR is much more beneficial than FBR and SR since it allows us to obtain a much higher selectivity.

\subsection{Oxidation}

The preferred way to produce maleic anhydride (MA) is currently based on the oxidation of butane, which replaced the previous synthetic route based on the partial oxidation of benzene. Butane in comparison to benzene presents some advantages like lower cost, lower toxicity and higher availability. However, the high flammability of butane limits the reaction process imposing to work at butane concentrations not higher than $2 \mathrm{vol} \%$. In the study of Cruz-Lòpez et al. [26], the use of a catalytic MR allowed to operate the oxidation reaction at higher butane concentration using a MFI/alumina membrane. The distribution of oxygen, used as a reactant, through the membrane allowed, in fact, the lowering of its concentration outside the flammability range. The reaction was catalyzed by a cobalt doped V/P/O (VPO) catalyst. A high MA selectivity conversion level of $75 \%$ was obtained with a productivity three times higher $\left(435 \mathrm{~mol} \mathrm{~m}^{-3} \mathrm{~h}^{-1}\right)$ than conventional reactors.

The partial oxidation of methane is used to convert $\mathrm{CH}_{4}$ to syngas $\left(\mathrm{CO}\right.$ and $\left.\mathrm{H}_{2}\right)$. The development of plants, at the commercial level, able to operate this conversion encountered some difficulties mainly because the reaction is partially exothermic creating local hot spot problems. MR can overcome this limitation controlling the reaction stoichiometry and the interaction of reactants. Knipe and Lin [27], for instance, operated the partial oxidation reaction of methane using a dense SrCoFeOx membrane using different catalysts (catalyst support $\gamma-\mathrm{Al}_{2} \mathrm{O}_{3}, \mathrm{La}_{0.6} \mathrm{Sr}_{0.4} \mathrm{Co}_{0.8} \mathrm{Fe}_{0.2} \mathrm{O}_{3}-\delta, \mathrm{Ni} / \gamma-\mathrm{Al}_{2} \mathrm{O}_{3}$ ). The membrane reactor with $\mathrm{Ni} / \gamma-\mathrm{Al}_{2} \mathrm{O}_{3}$ catalyst displayed the best performance in terms of $\mathrm{CH}_{4}$ conversion $\left(90 \%\right.$ at $900{ }^{\circ} \mathrm{C}$ ), $\mathrm{CO}$ selectivity (close to $100 \%$ ) and $\mathrm{O}_{2}$ flux (about $2.4 \mathrm{~mL} / \mathrm{cm}^{2} \mathrm{~min}$ ). In comparison, the blank membrane prepared with $\mathrm{Al}_{2} \mathrm{O}_{3}$, presented, under the same operative conditions, a $\mathrm{CH}_{4}$ conversion of about $19 \%$, $\mathrm{CO}$ selectivity of about 58 and an $\mathrm{O}_{2}$ flux of about $0.71 \mathrm{~mL} / \mathrm{cm}^{2} \mathrm{~min}$.

\section{Membranes in Carbonylation Reactions}

Despite the recognized efficiency of MRs in some specific chemical reactions reported above (such as esterification), the potentiality of this application is still in its infancy towards other chemical reactions such as carbonylations.

The synthesis of dimethyl carbonate (DMC) via oxidative carbonylation assisted by membrane technology was studied, for instance, by Li and Zhong [28]. DMC was traditionally produced from the phosgene-methanol process [29]. However, the high toxicity of phosgene led to the development of new synthetic routes that can be considered greener and safer. Among them, the most promising ones are based on the oxidative carbonylation of methanol and the direct synthesis of $\mathrm{DMC}$ from $\mathrm{CO}_{2}$ and methanol. In particular, the latter one is particularly appreciated due to the simplicity of the reaction (one single step), the low-cost of the reactants and the possibility to convert $\mathrm{CO}_{2}$ into a high-valued added organic compound [30]. One of the main limitations is, however, represented by the chemical inertness and high thermodynamic stability of $\mathrm{CO}_{2}$, which requires the use of different catalysts, high temperatures and pressures to carry out the reaction [31,32]. Li and Zhong [28] evaluated the use of three different supported membranes with copper catalyst supported on a $\mathrm{MgO}-\mathrm{SiO}_{2}$ substrate modified by KF for the synthesis of DMC. The membranes used for studying the conversion performance were represented by a mesoporous silica membrane supported on a $\mathrm{TiO}_{2} / \mathrm{K}-\mathrm{M}$ ceramic tube (membrane S), a polyimide-silica hybrid membrane supported on a $\mathrm{TiO}_{2} / \mathrm{K}-\mathrm{M}$ ceramic tube 
(membrane PS) and a polyimide-titania hybrid membrane supported on a $\mathrm{TiO}_{2} / \mathrm{K}-\mathrm{M}$ ceramic tube (membrane PT). The results were compared with a traditional conversion catalytic reaction (CCR). In $\mathrm{CCR}$, the reaction of $\mathrm{CO}_{2}$ with methanol leads to the production of $\mathrm{DMC}$ and $\mathrm{H}_{2} \mathrm{O}$ in the primary reaction and to the formation of $\mathrm{HCHO}$ and $\mathrm{CO}$ in the secondary side reaction. The conversion of methanol and the selectivity to DMC measured were of $6.55 \%$ and $90 \%$, respectively. Under the same operative conditions, all the three membranes displayed better performance in terms of conversion of methanol (8.1, 9.2 and 8.9 for the S, PS and PT membranes, respectively) and of selectivity to DMC (91.4, 96 and 93.3 for the S, PS and PT membranes, respectively). Improvements in performance were attributed to the hydrophilic nature of the membranes, which allowed a favorable permeation of the by-product $\mathrm{H}_{2} \mathrm{O}$ shifting the equilibrium towards the formation of the product. In particular, the best performance exhibited by the PT and PS membranes with respect to the $S$ one were related to the presence of carbonyl, amidocyanogen and carboxyl groups on the membrane surface, which favored the adsorption and permeation of water molecules. Even if the improvements were modest, it was demonstrated in this work, for the first time, that the introduction of membranes for the production of DMC can lead to an enhancement in catalytic reaction performance.

Yamanaka et al. [33] studied the DMC production through the electrochemical carbonylation of methanol and CO. A polytetrafluoroethylene (PTFE) porous membrane containing a Pd based catalyst acting as an anode and a PTFE membrane containing Pt black and acting as a cathode, were assembled into an electrolysis cell (Figure 3). The space between the two porous PTFE membranes was filled with a solution containing methanol and an electrolyte while a CO gas was fed through the anode side.

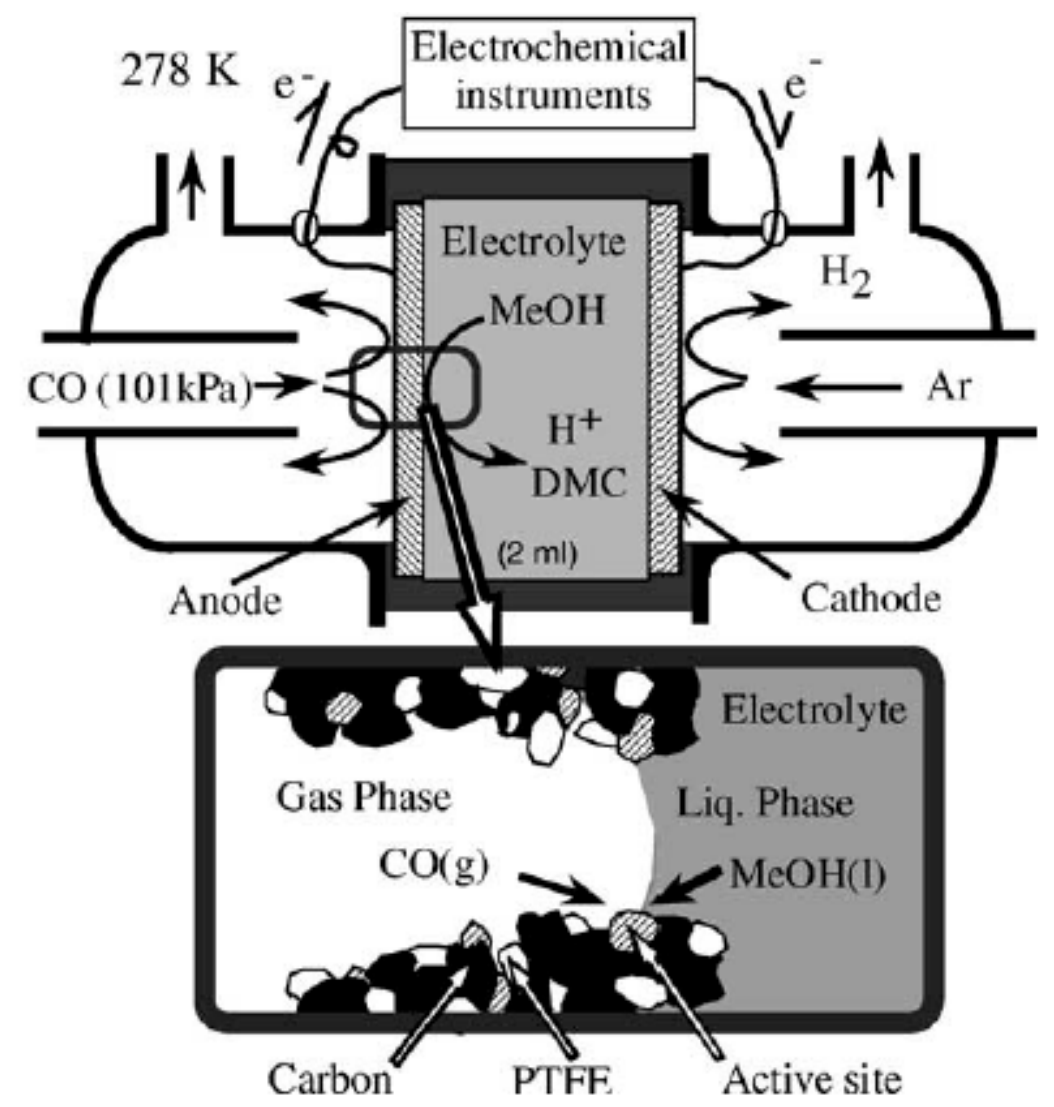

Figure 3. Schematic diagram of three-phase-boundary electrolysis for DMC synthesis [33].

The screening of different electrolytes showed that $\mathrm{NaClO}_{4}$ was the best one in terms of DMC production at $298 \mathrm{~K}$ and an electrolysis voltage of $3.5 \mathrm{~V}$. Dimethyl oxalate (DMO) was found to be the major by-product produced during the synthesis and its concentration increased as the formation of DMC increased. One of the advantages of using a three-phase boundary electrolysis method was the 
possibility of supplying more $\mathrm{CO}$ (higher partial pressure) promoting the selective carbonylation of DMC. Increasing the CO partial pressure (up to $100 \mathrm{kPa}$ ), in fact, the formation rate of DMC increased (up to $80 \mu \mathrm{mol} \mathrm{cm}{ }^{-2} \mathrm{~h}^{-1}$ at $100 \mathrm{kPa}$ ) while the formation rate of the by-product DMO decreased (about $10 \mu \mathrm{mol} \mathrm{cm}{ }^{-2} \mathrm{~h}^{-1}$ at $100 \mathrm{kPa}$ ). This three-phase boundary electrolysis method allowed the production of DMC with the following maxima values: TON(Pd) of $192 \mathrm{~h}^{-1}$, CO selectivity of $82 \%$ and DMC selectivity of $88 \%$.

The electrosynthesis of DMC from methanol and $\mathrm{CO}_{2}$ using the ionic liquid [bmim] [Br] and $\mathrm{CH}_{3} \mathrm{OK}$ was also performed by Garcia-Herrero et al. in two different works using cation and anion exchange membranes [34,35]. Among the five anion exchange membranes considered the best results were obtained with the FAB membrane, which was a based polyaromatic membrane with quaternary ammonium groups strongly cross-linked with polyether ether ketone (PEEK-WC). In $24 \mathrm{~h}$, in fact, a DMC production of $9.74 \mathrm{mmol} \mathrm{L}^{-1}$ was obtained with a maximum concentration of $13.74 \mathrm{mmol} \mathrm{L}^{-1}$ [34]. When a cationic exchange membrane based on Nafion 117 was used [35], a similar concentration of DMC produced was observed. The cationic or anionic character of the membrane, therefore, seemed not to play a crucial role in DMC production.

The main difference between the two approaches could be observed in the presence and concentration of by-products. In case of a cationic exchange membrane, in fact, tetramethyl orthocarbonate (OC) and dimethoxymethane (DMM) were detected. When an anionic exchange membrane was used, on the contrary, the two by-products were not identified (considering the same experiment time). However, when no membrane was used at all, a final concentration of $85 \mathrm{mmol} \mathrm{L}^{-1}$ of DMC was obtained (six times higher than the experiments carried out with membranes). Although better performance were observed when the configuration with no membrane was used, the results obtained with the membranes were, in any case, considered interesting and worth being more deeply investigated as preliminary new approaches for the electrosynthesis of DMC from methanol and $\mathrm{CO}_{2}$ using the ionic liquid $[\mathrm{bmim}][\mathrm{Br}]$ and $\mathrm{CH}_{3} \mathrm{OK}$.

\section{Pervaporation in Separating Derived Products from Carbonylation Reactions}

Today, PV, a highly selective membrane-based separation process, has emerged as a potential candidate for the separation, recovery and purification of derived products from carbonylation reactions. Generally, PV is able to separate azeotropic, close boiling-point, diluted and thermally unstable liquid mixtures, where a phase change from liquid to vapor takes place [36]. PV has become attractive for scientists according to its several advantages, such as low energy consumption and lack of any solvent requirements [2,17], as well as the fact that it is not limited by the vapor-liquid equilibrium. In principle, the liquid feed mixture is in direct contact with the "selective" side of the PV membrane, while the permeate (the stream collected at the other side of the membrane) is in the vapor phase, which is enriched with the permeating species having a higher affinity for the membrane [37]. Figure 4 shows the affinity of a hydrophilic or hydrophobic membrane towards specific target compounds. 
Hydrophilic

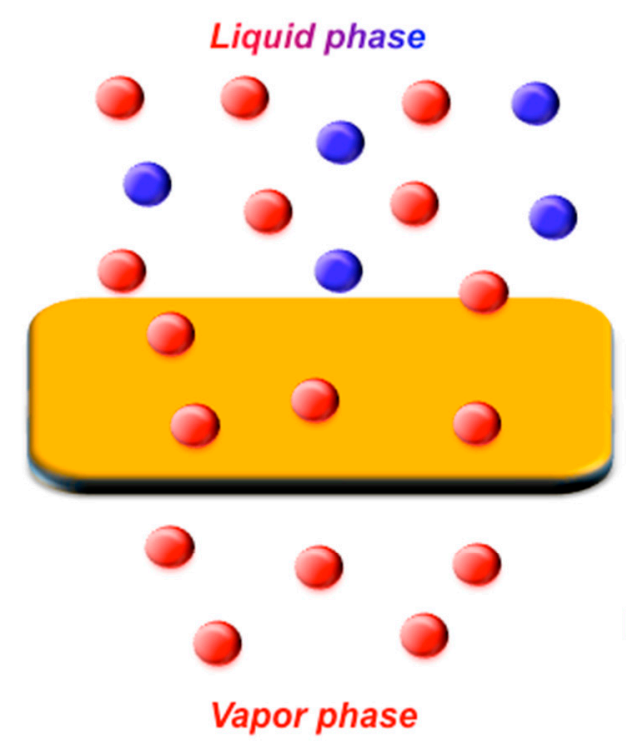

\section{Hydrophobic}

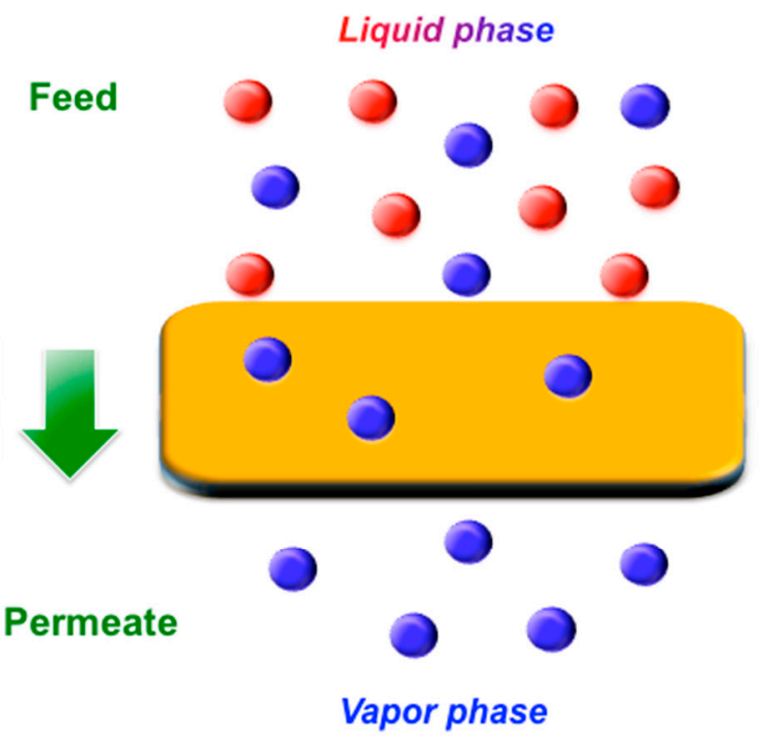

\section{O Polar O Non- polar}

Figure 4. Graphical depiction of the separation mechanisms in pervaporation (PV) for hydrophilic and hydrophobic polymeric membranes towards mixtures of polar and non-polar compounds.

Table 1 displays the most relevant findings in literature about the use of PV in separating different derived products from carbonylation reactions. It is likely that DMC has been the most explored chemical in the field. The importance of DMC deals with its use as a green chemical agent [38]. DMC is indeed considered as a potential candidate for the replacement of methyl-tert-butyl ether (MTBE) as an oxygenated fuel additive of gasoline or diesel oil. These purposes have rapidly promoted the increasing of its application in the last years [39]. The synthesis of DMC is typically carried by means of several routes, such as phosgenation of methanol $(\mathrm{MeOH})$, urea methanolysis, transesterification of cyclic carbonates, direct reaction of $\mathrm{CO}_{2}$ with $\mathrm{MeOH}$ and, of course, oxidative carbonylation of $\mathrm{MeOH}$ [32]. However, in all aforementioned methodologies, DMC and MeOH form a minimum boiling azeotrope containing almost $70 \mathrm{wt} \%$ methanol and traces of other polar compounds (e.g., water). The conventional distillation (e.g., extractive distillation and pressure-swing distillation) has been the primary technology used for the purification/separation of DMC [38]. Today, according to the several drawbacks of distillation (e.g., high-energy demand), PV has started to be proposed for the purification of DMC. At this point, PV membranes are primarily tested for such MeOH-DMC separation [40]. For instance, Won et al. (2002) proposed hydrophilic chitosan membranes to selectively remove polar compounds (e.g., water and $\mathrm{MeOH}$ ) from ternary azeotropic mixtures (i.e., DMC, water and $\mathrm{MeOH}$ ). This chitosan membrane demonstrated its capability of purifying DMC, in which permeate fluxes of water and methanol were about 0.102 and $0.250 \mathrm{~kg} \mathrm{~m}^{-2} \mathrm{~h}^{-1}$, respectively. Moreover, the authors stated that the feed composition of the azeotropic mixture plays an important role on DMC purification. For instance, the authors found out that the total permeation flux tended to decrease as the feed water content increased, while the flux began to increase when the feed water content was relatively low. Similarly, the authors also reported that a cross-linked chitosan membrane can be used effectively to break the DMC-MeOH azeotrope, as well as remove a small amount of water from DMC [41]. In particular, it was demonstrated that the coupling effect is particularly influencing the PV separation of multi-component mixtures due to interactions among the permeating compounds. In other words, the presence of one component affects the permeation of the other two components. Such magnitude 
of the coupling effect was influenced by the specific feed composition and operating temperature (in the range of $\left.25-55^{\circ} \mathrm{C}\right)[39,41]$.

Recently, Li et al. (2018) used a modified membrane based on PEEK-WC polymer for the PV separation of $\mathrm{MeOH}-\mathrm{DMC}$. The transmembrane flux was temperature dependent with a value of $0.14 \mathrm{~kg} \mathrm{~m}^{-2} \mathrm{~h}^{-1}$ (at $30^{\circ} \mathrm{C}$ ) at low concentration of $\mathrm{MeOH}(10 \mathrm{~mol} \%)$, having its highest separation factor around 13.4. Furthermore, high concentration of $\mathrm{MeOH}$ resulted in a high permeance of DMC due to a dragging effect. It is important to mention that this type of membrane does not offer a superior separation performance, however, its potential deals with its excellent mechanical properties during the overall experimental period.

Wang et al. (2007) studied the blending of PAA-PVA in the preparation of membranes for $\mathrm{MeOH}-\mathrm{DMC}$ separation. Such membranes tended to display an increase in $\mathrm{MeOH}$ flux by increasing the $\mathrm{MeOH}$ concentration (from 30 to $90 \mathrm{wt} \%$ ) in feed mixture, this behavior contributed to increasing the selectivity as well. Nevertheless, as a drawback, the selectivity of the PAA-PVA blend membranes was poor when feed contained low $\mathrm{MeOH}$ concentration, especially lower than $10 \mathrm{wt} \% \mathrm{MeOH}$. More recently, the authors evaluated the performance of those PAA-PVA blend membranes by applying a cross-linking procedure [44]. In this sense, membranes with different glutaraldehyde content were prepared. At $40 \mathrm{wt} \% \mathrm{MeOH}$ concentration, the membranes displayed a decrease of the separation factor as the temperature increased (in the range of $50-70^{\circ} \mathrm{C}$ ). This behavior is typical of polymeric membranes and related to the polymeric carbon chains motion induced by temperature, in which the transport of larger molecules is facilitated [37]. Finally, these cross-linked PAA-PVA membranes reached a maximum separation factor of about 275 (at $50^{\circ} \mathrm{C}$ ). Moreover, such a study reported that the separation factors also decreased but the fluxes increased with increasing $\mathrm{MeOH}$ concentration in feed from 40 to $70 \mathrm{wt} \%$. This result can be explained considering the $\mathrm{MeOH}$ plasticization effect toward the membrane. As the $\mathrm{MeOH}$ concentration in the feed increased, the membrane becomes more swollen because of a stronger affinity with it. Consequently, the polymeric chains tend to be more flexible and the energy required for diffusive transport is less, resulting in a flux increase [44]. 
Table 1. Current findings of PV application aiming the separation of products derived from carbonylation reactions.

\begin{tabular}{|c|c|c|c|c|c|}
\hline Mixture & Aim & Membrane Type & $\begin{array}{l}\text { Operating Conditions } \\
\text { (Temperature, Pressure) }\end{array}$ & Performance & Reference \\
\hline Water/methanol/DMC & DMC purification & Chitosan membrane & $55^{\circ} \mathrm{C}, 2-3$ mbar & $\begin{array}{l}\text { Water flux: } 0.102 \mathrm{~kg} / \mathrm{m}^{2} \mathrm{~h} \\
\text { Methanol flux: } 0.250 \mathrm{~kg} / \mathrm{m}^{2} \mathrm{~h} \\
\text { DMC flux: } 0.011 \mathrm{~kg} / \mathrm{m}^{2} \mathrm{~h} \\
\text { Separation factor: } 5.0\end{array}$ & [39] \\
\hline Methanol/DMC & DMC purification & PEEK-WC membrane & $30^{\circ} \mathrm{C}, 5 \mathrm{mbar}$ & $\begin{array}{l}\text { Total flux: } 0.14 \mathrm{~kg} / \mathrm{m}^{2} \mathrm{~h} \\
\text { Separation factor: } 13.4\end{array}$ & [42] \\
\hline Water/methanol/DMC & DMC purification & $\begin{array}{l}\text { Cross-linked chitosan } \\
\text { membrane }\end{array}$ & $25^{\circ} \mathrm{C}, 2-3$ mbar & $\begin{array}{l}\text { Total flux: } 0.180 \mathrm{~kg} / \mathrm{m}^{2} \mathrm{~h} \\
\text { Separation factor: } 85\end{array}$ & [41] \\
\hline Methanol/DMC & Methanol removal & $\begin{array}{l}\text { PAA-PVA blend } \\
\text { membrane }\end{array}$ & $60^{\circ} \mathrm{C}, 2 \mathrm{mbar}$ & $\begin{array}{l}\text { Total flux: } 0.577 \mathrm{~kg} / \mathrm{m}^{2} \mathrm{~h} \\
\text { Separation factor: } 13\end{array}$ & [43] \\
\hline Methanol/DMC & Methanol removal & $\begin{array}{l}\text { Cross-linked PAA-PVA } \\
\text { blend membrane }\end{array}$ & $50{ }^{\circ} \mathrm{C}, 2 \mathrm{mbar}$ & $\begin{array}{l}\text { Total flux: } 0.040 \mathrm{~kg} / \mathrm{m}^{2} \mathrm{~h} \\
\text { Separation factor: } 275\end{array}$ & [44] \\
\hline Methanol/DMC & Methanol removal & $\mathrm{SiO}_{2}$ membranes & $50^{\circ} \mathrm{C}, 0 \mathrm{mbar}$ & $\begin{array}{l}\text { Total flux: } 180 \mathrm{~mol} / \mathrm{m}^{2} \mathrm{~h} \\
\text { Separation factor: } 140\end{array}$ & [45] \\
\hline Water/DMC & Water removal & GO membranes & $25^{\circ} \mathrm{C}, 3 \mathrm{mbar}$ & $\begin{array}{l}\text { Total flux: } 1.702 \mathrm{~kg} / \mathrm{m}^{2} \mathrm{~h} \\
\text { Separation factor: } 740\end{array}$ & [46] \\
\hline DMC/Methanol & DMC separation & $\begin{array}{l}\text { Organophilic ZIF-71 } \\
\text { membranes }\end{array}$ & $25^{\circ} \mathrm{C}$ & $\begin{array}{l}\text { Total flux: } 0.271 \mathrm{~kg} / \mathrm{m}^{2} \mathrm{~h} \\
\text { Separation factor: } 8.0\end{array}$ & [47] \\
\hline Methanol/DMC & DMC purification & $\begin{array}{l}\text { Composite polyamide- } 6 \\
\text { membrane }\end{array}$ & $30^{\circ} \mathrm{C}$ & $\begin{array}{l}\text { Methanol flux: } 0.592 \mathrm{~kg} / \mathrm{m}^{2} \mathrm{~h} \\
\text { Separation factor: } 3\end{array}$ & [48] \\
\hline Methanol/DMC & DMC purification & $\begin{array}{l}\text { STA-chitosan hybrid } \\
\text { membranes }\end{array}$ & $50^{\circ} \mathrm{C}, 4 \mathrm{mbar}$ & $\begin{array}{l}\text { Total flux: } 1.163 \mathrm{~kg} / \mathrm{m}^{2} \mathrm{~h} \\
\text { Separation factor: } 67.3\end{array}$ & [49] \\
\hline Methanol/DMC & Methanol removal & $\begin{array}{c}\text { Silica-chitosan composite } \\
\text { membranes }\end{array}$ & $50^{\circ} \mathrm{C}, 3 \mathrm{mbar}$ & $\begin{array}{l}\text { Total flux: } 1.265 \mathrm{~kg} / \mathrm{m}^{2} \mathrm{~h} \\
\text { Separation factor: } 30.1\end{array}$ & [50] \\
\hline Methanol/DMC & Methanol removal & $\begin{array}{c}\text { ZSM-5-chitosan } \\
\text { composite membranes }\end{array}$ & $25^{\circ} \mathrm{C}, 13 \mathrm{mbar}$ & $\begin{array}{l}\text { Total flux: } 0.056 \mathrm{~kg} / \mathrm{m}^{2} \mathrm{~h} \\
\text { Separation factor: } 29.4\end{array}$ & [51] \\
\hline DMC/Methanol & DMC separation & $\begin{array}{l}\text { Nanosilica-filled PDMS } \\
\text { membranes }\end{array}$ & $40^{\circ} \mathrm{C}, 1 \mathrm{mbar}$ & $\begin{array}{l}\text { Total flux: } 1.5 \mathrm{~kg} / \mathrm{m}^{2} \mathrm{~h} \\
\text { Separation factor: } 8\end{array}$ & [52] \\
\hline DMC/Methanol & DMC separation & $\begin{array}{l}\text { Nanosilica-filled PDMS } \\
\text { membranes }\end{array}$ & $40^{\circ} \mathrm{C}, 1 \mathrm{mbar}$ & $\begin{array}{l}\text { Total flux: } 0.702 \mathrm{~kg} / \mathrm{m}^{2} \mathrm{~h} \\
\text { Separation factor: } 3.9\end{array}$ & [53] \\
\hline DMC/Methanol & DMC separation & $\begin{array}{l}\text { Modified MCM-41-filled } \\
\text { PDMS membranes }\end{array}$ & $40^{\circ} \mathrm{C}, 1 \mathrm{mbar}$ & $\begin{array}{l}\text { Total flux: } 1.157 \mathrm{~kg} / \mathrm{m}^{2} \mathrm{~h} \\
\text { Separation factor: } 3.5\end{array}$ & [54] \\
\hline DMC/Methanol & DMC separation & $\begin{array}{l}\text { PDMS-PVDF composite } \\
\text { membrane }\end{array}$ & $40^{\circ} \mathrm{C}, 2 \mathrm{mbar}$ & $\begin{array}{l}\text { Total flux: } 0.48 \mathrm{~kg} / \mathrm{m}^{2} \mathrm{~h} \\
\text { Separation factor: } 3.9\end{array}$ & [55] \\
\hline
\end{tabular}


Since $\mathrm{MeOH}$ is a more polar compound and has a smaller molecular size than DMC, the common strategy for the separation of these mixtures, is based on the use of hydrophilic polymers (e.g., PVA, PAA, chitosan and PEEK-WC), which may facilitate the $\mathrm{MeOH}$ transport through the membrane. However, there are other types of membranes, like inorganic ones, which have excellent stability against organic solvents [56], and better molecular sieving than polymeric membranes. In this way, several authors have also proposed the use of inorganic membranes. Tsuru et al. (2011), for instance, used inorganic porous silica membranes with different pore size (in the range 0.3-1.2 nm). Especially, silica membranes with a pore size of $0.3 \mathrm{~nm}$ showed the highest permselectivity for $\mathrm{MeOH}$, having a separation factor and a MeOH flux of about 140 and $180 \mathrm{~mol} \mathrm{~m}^{-2} \mathrm{~h}^{-1}$ (at $\mathrm{MeOH} 50 \mathrm{~mol} \%$ and $50{ }^{\circ} \mathrm{C}$ ), respectively. Additionally, the greater adsorption capacity of silica membranes towards $\mathrm{MeOH}$ compared to DMC was demonstrated. Likewise, Huang et al. (2014) proposed a highly hydrophilic material, like graphene oxide (GO), for the removal of water from DMC. These GO membranes showed permeation fluxes and a separation factor of $1.702 \mathrm{~kg} \mathrm{~m}^{-2} \mathrm{~h}^{-1}$ and 740 , respectively. It has been documented that the defects in GO flakes generated by the oxidation reaction, and the d-spacing between GO flakes, are the main transport pathway for molecules through the GO membrane. In fact, GO fillers favor the preferential transport of polar molecules (e.g., water). This is due to the fact that GO laminates simultaneously have oxidized (proper GO, hydrophilic) and non-oxidized (graphene, hydrophobic) regions. These regions of graphene sheets possess a d-spacing of ca. $5 \AA$ [57], which is enough to host a monolayer of water. It has been speculated that these empty spaces form a network of pristine-graphene capillaries within GO laminates [58], which would facilitate the water transport. Particularly, Nair et al. (2012) has demonstrated that the water permeation rate can be at least five orders of magnitude higher than that of the others components [58,59]. This GO property may allow obtaining a surprisingly high PV performance of such membranes during the water removal form water-DMC systems.

To overcome selectivity-permeability limitations of polymeric membranes and enhance their separation performance, filler materials have been currently incorporated into polymeric membranes, leading to the development of mixed matrix membranes (MMMs) [60,61]. MMMs are often considered as the next membrane generation since they combine the benefits of inorganic and polymeric membranes [62,63], and therefore able to ideally achieve a synergistic performance. In particular, these MMMs have shown great improvements in selective transport for separating DMC. For instance, Kopec et al. (2013) proposed MMMs based on $\mathrm{ZrO}_{2}$-polyamide- 6 for the selective removal of $\mathrm{MeOH}$ from $\mathrm{MeOH}-\mathrm{DMC}$ mixtures. It was found that membranes were selective to $\mathrm{MeOH}$ displaying a pervaporation separation index of 1602. The authors also addressed that the presence of water (in a water-MeOH-DMC mixture) causes a decrease of the separation factor of the investigated membranes. Generally, this effect is explained by the phenomena of competitive transport between water and $\mathrm{MeOH}$ molecules. Water flux indeed increased while the flux of $\mathrm{MeOH}$ decreased because the transport through the polar membrane is greater for a more polar compound (i.e., water) [48].

Chen et al. (2008) enhanced the performance of chitosan membranes by incorporating silicotungstic acid hydrate (STA). The hybrid membranes were tested for the $\mathrm{MeOH}$ removal from $\mathrm{MeOH}-\mathrm{DMC}$ mixtures. Such membranes displayed a remarkable separation performance with a flux of $1.163 \mathrm{~kg} \mathrm{~m}^{-2} \mathrm{~h}^{-1}$ and separation factor of 67.3 (at $50{ }^{\circ} \mathrm{C}$ at the feed $\mathrm{MeOH}$ content $10 \mathrm{wt} \%$ ). In addition, it was noticed that the separation factor decreased with increasing feed temperature or $\mathrm{MeOH}$ content, however, the flux increased with increasing feed temperature or $\mathrm{MeOH}$ content. On the other hand, the separation factor tended to increase with an STA content increase, which reached a maximum at $8 \mathrm{wt} \%$ STA content. According to the author's findings, the increase of the separation factor could be explained by the hydrophilicity enhancement of the membrane. In theory, the - $\mathrm{OH}$ on the surface of STA can form $\mathrm{H}$-bonds with the $-\mathrm{OH}$ or $-\mathrm{NH}_{2}$ of chitosan. Therefore, the amorphous region of the chitosan may be enhanced by incorporating STA, and, therefore, may improve the performance of the chitosan membranes resulting in a structure with a more compact morphology [49]. Previously, the authors also improved the PV separation of $\mathrm{MeOH}-\mathrm{DMC}$ mixtures by embedding silica 
in chitosan membranes. In this study, the sorption selectivity of the chitosan membranes was greatly improved as well. For instance, the composite membranes showed superior separation behavior over pristine membranes with a flux of $1.265 \mathrm{~kg} \mathrm{~m}^{-2} \mathrm{~h}^{-1}$ and a separation factor of 30.1 (at $70 \mathrm{wt} \% \mathrm{MeOH}$ in feed, $50{ }^{\circ} \mathrm{C}$ ) [50]. It is important to mention that such composite membranes displayed a stable separation performance over $350 \mathrm{~min}$ operating time (in the range of $30-50^{\circ} \mathrm{C}$ ).

To date, the incorporation of hydrophilic materials into hydrophilic polymers for the preparation of MMMs has allowed improving the removal of the polar compound (i.e., methanol) from $\mathrm{MeOH}-\mathrm{DMC}$ mixtures. Nevertheless, the separation of the non-polar compounds can also be reached by preparing MMMs with a hydrophobic nature [52-54]. For example, hydrophobic nano-silica filled polydimethylsiloxane (PDMS) membranes were prepared and used in DMC separation from the DMC-MeOH mixture [52,53]. The membranes containing $15 \mathrm{wt} \%$ of silica showed the highest PV separation factor of 3.94, with a permeate flux of $0.702 \mathrm{~kg} \mathrm{~m}^{-2} \mathrm{~h}^{-1}$ for the DMC-MeOH mixture separation [53]. Moreover, the incorporation of the inorganic material allowed suppressing the membrane swelling and enhancing the plasticization resistance. In addition to the acceptable PV performance, good membrane stability and operation durability are also needed for a possible large scale application [64]. Therefore, long-term PV experiments are needed. In this regard, Wang et al. [53] also reported that the performance of such nano-silica-PDMS membranes remained relatively constant over seven operation days.

The chemical modification is a current approach used for the enhancement of fillers properties. The chemical modification generally contributes to improve the filler-polymer interactions, and therefore enhanced separation performance [61,65]. Wang et al. [54] modified mesoporous MCM-41 silica spheres by means of silylation. After this procedure, the surface property of MCM- 41 silica changed from hydrophilic to hydrophobic. The modified MCM-41 spheres were embedded into a PDMS matrix. The chemical modification clearly enhanced the interfacial adhesion between polymer and modified material. The modified MMMs displayed an improved total flux $\left(1.157 \mathrm{~kg} \mathrm{~m}^{-2} \mathrm{~h}^{-1}\right)$ and separation factor (3.5) compared to the PDMS membrane $\left(0.884 \mathrm{~kg} \mathrm{~m}^{-2} \mathrm{~h}^{-1}, 3.0\right)$.

\section{Conclusions, Challenges and Future Perspectives}

Membranes are gaining more and more attention in assisting chemical reactions. Membrane reactors are able to combine several advantages by improving the reaction yield, the purity of the products and requiring milder conditions to operate. Nevertheless, the use of membranes is already a reality for some catalytic reactions such as esterification, while their use in assisting carbonylation reactions is still limited. Currently, the synthesis of DMC from methanol and $\mathrm{CO}_{2}$ represent the only important carbonylation reaction where membranes have started to be applied.

If in carbonylation reactions the use of membranes is still restricted, in the recovery of carbonylation reaction products, membrane processes already play an important role. To date, according to the recent findings reported in the literature, PV has demonstrated its ability to separate the products derived from carbonylation reactions. DMC has been the main product separated from different types of azeotropic mixtures (e.g., water-DMC, $\mathrm{MeOH}-\mathrm{DMC}$ and water-MeOH-DMC), in which hydrophilic polymeric membranes (e.g., PVA, PAA, chitosan, PEEK-WC and polyamide) and MMMs have been used for the removal of polar compounds (e.g., water and $\mathrm{MeOH}$ ). However, hydrophobic membranes, such as PDMS and PVDF, can also be used for the selective separation of DMC. Finally, the suitable selection of the membrane nature and operating conditions play an important role in the separation performance of PV membranes. In the future, based on the successful results about separation of DMC, it is likely that some other products derived from carbonylation reactions, such as diphenylurea, diphenylcarbonate and isocyanates, will be attempted to be separated using membrane-based technologies.

The main challenges still open for a full exploitation of membranes in this field are represented by the development of novel materials more and more performing (in terms of flux and selectivity) and highly resistant to harsh conditions (pressure, temperature and chemicals). In the next future, a dominant role in this direction could be played by the MMMs, which are able to synergistically 
combine the benefits of polymeric materials (low cost and easy processability) with inorganic ones (high resistance) thus widening the use of membranes in a large variety of chemical reactions.

Author Contributions: Conceptualization, B.G., R.M., A.F., writing-original draft preparation, F.G, R.C.-M.; writing—review and editing, F.G., R.C.-M.; visualization, B.G., A.F., R.M.; supervision, B.G., A.F., R.M.

Funding: This research received no external funding.

Conflicts of Interest: The authors declare no conflict of interest.

\section{References}

1. Figoli, A.; Simone, S.; Drioli, E. Polymeric membranes. In Membrane Fabrication; Hilal, N., Ismail, A.F., Wright, C., Eds.; Taylor \& Francis Group: Abingdon, UK, 2015; pp. 1-42.

2. Figoli, A.; Santoro, S.; Galiano, F.; Basile, A. Pervaporation membranes: Preparation, characterization, and application. In Pervaporation, Vapour Permeation and Membrane Distillation: Principles and Applications; Woodhead Publishing: Cambridge, UK, 2015; ISBN 9781782422563.

3. Bayer, E.; Schurig, V. Lösliche Metallkomplexe von Polymeren zur Katalyse. Angew. Chem. 1975, 87, 484-485. [CrossRef]

4. Bayer, E; Schurig, V. Soluble metal complexes of polymers for catalysis. Angew. Chem. Int. Ed. Engl. 1975, 14, 493-494. [CrossRef]

5. Unlu, D.; Hilmioglu, N.D. Pervaporation catalytic membrane reactor application over functional chitosan membrane. J. Membr. Sci. 2018, 559, 138-147. [CrossRef]

6. Sirkar, K.K.; Shanbhag, P.V.; Kovvali, A.S. Membrane in a reactor: A functional perspective. Ind. Eng. Chem. Res. 1999, 38, 3715-3737. [CrossRef]

7. Dittmeyer, R.; Svajda, K.; Reif, M. A review of catalytic membrane layers for gas/liquid reactions. Top. Catal. 2004, 29, 3-27. [CrossRef]

8. Vankelecom, I.F.J. Polymeric membranes in catalytic reactors. Chem. Rev. 2002, 102, 3779-3810. [CrossRef] [PubMed]

9. Poźniak, G.; Krajewska, B.; Trochimczuk, W. Urease immobilized on modified polysulphone membrane: Preparation and properties. Biomaterials 1995, 16, 129-134. [CrossRef]

10. Ozdemir, S.S.; Buonomenna, M.G.; Drioli, E. Catalytic polymeric membranes: Preparation and application. Appl. Catal. A Gen. 2006, 307, 167-183. [CrossRef]

11. Hsieh, H.P. Inorganic membrane reactors. Catal. Rev. Sci. Eng. 1991, 33, 1-70. [CrossRef]

12. Fard, A.K.; McKay, G.; Buekenhoudt, A.; Al Sulaiti, H.; Motmans, F.; Khraisheh, M.; Atieh, M. Inorganic membranes: Preparation and application for water treatment and desalination. Materials (Basel) 2018, 11, 74.

13. Cot, L.; Guizard, C.; Julbe, A.; Larbot, A. Preparation and application of inorganic membranes. In Membrane Processes in Separation and Purification; Crespo, J.G., Böddeker, K.W., Eds.; Springer: New York, NY, USA, 1994; pp. 431-442.

14. Yang, S.; Gu, J.S.; Yu, H.Y.; Zhou, J.; Li, S.F.; Wu, X.M.; Wang, L. Polypropylene membrane surface modification by RAFT grafting polymerization and $\mathrm{TiO}_{2}$ photocatalysts immobilization for phenol decomposition in a photocatalytic membrane reactor. Sep. Purif. Technol. 2011, 83, 157-165. [CrossRef]

15. Benhabiles, O.; Galiano, F.; Marino, T.; Mahmoudi, H.; Lounici, H.; Figoli, A. Preparation and characterization of $\mathrm{TiO}_{2}-\mathrm{PVDF} / \mathrm{PMMA}$ blend membranes using an alternative non-toxic solvent for UF/MF and photocatalytic application. Molecules 2019, 24, 724. [CrossRef] [PubMed]

16. Lilja, J.; Aumo, J.; Salmi, T.; Murzin, D.Y.; Mäki-Arvela, P.; Sundell, M.; Ekman, K.; Peltonen, R.; Vainio, H. Kinetics of esterification of propanoic acid with methanol over a fibrous polymer-supported sulphonic acid catalyst. Appl. Catal. A Gen. 2002, 228, 253-267. [CrossRef]

17. Castro-Muñoz, R.; De La Iglesia, Ó.; Fila, V.; Téllez, C.; Coronas, J. Pervaporation-assisted esterification reactions by means of mixed matrix membranes. Ind. Eng. Chem. Res. 2018, 57, 15998-16011. [CrossRef]

18. Kumar, R.; Mahajani, S.M. Esterification of lactic acid with n-butanol by reactive distillation. Ind. Eng. Chem. Res. 2007, 46, 6873-6882. [CrossRef]

19. Bagnell, L.; Cavell, K.; Hodges, A.M.; Mau, A.W.H.; Seen, A.J. The use of catalytically active pervaporation membranes in esterification reactions to simultaneously increase product yield, membrane permselectivity and flux. J. Membr. Sci. 1993, 85, 291-299. [CrossRef] 
20. De Souza Figueiredo, K.C.; Salim, V.M.M.; Borges, C.P. Synthesis and characterization of a catalytic membrane for pervaporation-assisted esterification reactors. Catal. Today 2008, 133, 809-814. [CrossRef]

21. Zhang, W.; Qing, W.; Chen, N.; Ren, Z.; Chen, J.; Sun, W. Enhancement of esterification conversion using novel composite catalytically active pervaporation membranes. J. Membr. Sci. 2014, 451, 285-292. [CrossRef]

22. El-Zanati, E.; Abdallah, H. Esterification of ethyl hexanoic acid using flow-through catalytic membrane reactor. Catal. Ind. 2015, 7, 91-97. [CrossRef]

23. Centi, G.; Dittmeyer, R.; Perathoner, S.; Reif, M. Tubular Inorganic catalytic membrane reactors: Advantages and performance in multiphase hydrogenation reactions. Catal. Today 2003, 79-80, 139-149. [CrossRef]

24. Schmidt, A.; Haidar, R.; Schomäcker, R. Selectivity of partial hydrogenation reactions performed in a pore-through-flow catalytic membrane reactor. Catal. Today 2005, 104, 305-312. [CrossRef]

25. Bagnato, G.; Figoli, A.; Ursino, C.; Galiano, F.; Sanna, A. A novel Ru-polyethersulfone (PES) catalytic membrane for highly efficient and selective hydrogenation of furfural to furfuryl alcohol. J. Mater. Chem. A 2018, 6, 4955-4965. [CrossRef]

26. Cruz-López, A.; Guilhaume, N.; Miachon, S.; Dalmon, J.A. Selective oxidation of butane to maleic anhydride in a catalytic membrane reactor adapted to rich butane feed. Catal. Today 2005, 107, 949-956. [CrossRef]

27. Kniep, J.; Lin, Y.S. Partial oxidation of methane and oxygen permeation in SrCoFeOx membrane reactor with different catalysts. Ind. Eng. Chem. Res. 2011, 50, 7941-7948. [CrossRef]

28. Li, C.F.; Zhong, S.H. Study on application of membrane reactor in direct synthesis DMC from CO2 and $\mathrm{CH} 3 \mathrm{OH}$ over $\mathrm{Cu}-\mathrm{KF} / \mathrm{MgSiO}$ catalyst. Catal. Today 2003, 82, 83-90. [CrossRef]

29. Delledonne, D.; Rivetti, F.; Romano, U. Developments in the production and application of dimethylcarbonate. Appl. Catal. A Gen. 2001, 221, 241-251. [CrossRef]

30. Eta, V.; Mäki-Arvela, P.; Wärn, J.; Salmi, T.; Mikkola, J.P.; Murzin, D.Y. Kinetics of dimethyl carbonate synthesis from methanol and carbon dioxide over $\mathrm{ZrO}_{2}-\mathrm{MgO}$ catalyst in the presence of butylene oxide as additive. Appl. Catal. A Gen. 2011, 404, 39-46. [CrossRef]

31. Sakakura, T.; Kohno, K. The synthesis of organic carbonates from carbon dioxide. Chem. Commun. 2009, 11, $1312-1330$. [CrossRef]

32. Eta, V.; Mäki-Arvela, P.; Leino, A.R.; Kordás, K.; Salmi, T.; Murzin, D.Y.; Mikkola, J.P. Synthesis of dimethyl carbonate from methanol and carbon dioxide: Circumventing thermodynamic limitations. Ind. Eng. Chem. Res. 2010, 49, 9609-9617. [CrossRef]

33. Yamanaka, I.; Funakawa, A.; Otsuka, K. Electrocatalytic synthesis of DMC over the Pd/VGCF membrane anode by gas-liquid-solid phase-boundary electrolysis. J. Catal. 2004, 221, 110-118. [CrossRef]

34. Garcia-Herrero, I.; Alvarez-Guerra, M.; Irabien, A. Electrosynthesis of dimethyl carbonate from methanol and $\mathrm{CO} 2$ using potassium methoxide and the ionic liquid [bmim] [Br] in a filter-press cell: A study of the influence of cell configuration. J. Chem. Technol. Biotechnol. 2016, 91, 507-513. [CrossRef]

35. Garcia-Herrero, I.; Alvarez-Guerra, M.; Irabien, A. CO2 electro-valorization to dimethyl carbonate from methanol using potassium methoxide and the ionic liquid [bmim] $[\mathrm{Br}]$ in a filter-press electrochemical cell. J. Chem. Technol. Biotechnol. 2015, 90, 1433-1438. [CrossRef]

36. Van Der Bruggen, B.; Luis, P. Pervaporation as a tool in chemical engineering: A new era? Curr. Opin. Chem. Eng. 2014, 4, 47-53. [CrossRef]

37. Baker, R.W.; Wijmans, J.G.; Huang, Y. Permeability, permeance and selectivity: A preferred way of reporting pervaporation performance data. J. Membr. Sci. 2010, 348, 346-352. [CrossRef]

38. Wei, H.; Wang, F.; Zhang, J.; Liao, B.; Zhao, N.; Xiao, F.; Wei, W.; Sun, Y. Design and control of dimethyl carbonate-Methanol separation via pressure-swing distillation. Ind. Eng. Chem. Res. 2013, 52, 11463-11478. [CrossRef]

39. Won, W.; Feng, X.; Lawless, D. Pervaporation with chitosan membranes: Separation of dimethyl carbonate/methanol/water mixtures. J. Membr. Sci. 2002, 209, 493-508. [CrossRef]

40. Smitha, B.; Suhanya, D.; Sridhar, S.; Ramakrishna, M. Separation of organic-Organic mixtures by pervaporation-A review. J. Membr. Sci. 2004, 241,1-21. [CrossRef]

41. Won, W.; Feng, X.; Lawless, D. Separation of dimethyl carbonate/methanol/water mixtures by pervaporation using crosslinked chitosan membranes. Sep. Purif. Technol. 2003, 31, 129-140. [CrossRef]

42. Li, W.; Galiano, F.; Estager, J.; Monbaliu, J.M.; Debecker, D.P.; Figoli, A.; Luis, P. Sorption and pervaporation study of methanol/dimethyl carbonate mixture with poly (etheretherketone) (PEEK-WC) membrane. J. Membr. Sci. 2018, 567, 303-310. [CrossRef] 
43. Wang, L.; Li, J.; Lin, Y.; Chen, C. Separation of dimethyl carbonate/methanol mixtures by pervaporation with poly (acrylic acid)/poly (vinyl alcohol) blend membranes. J. Membr. Sci. 2007, 305, 238-246. [CrossRef]

44. Wang, L.; Li, J.; Lin, Y.; Chen, C. Crosslinked poly (vinyl alcohol) membranes for separation of dimethyl carbonate/methanol mixtures by pervaporation. Chem. Eng. J. 2009, 146, 71-78. [CrossRef]

45. Tsuru, T.; Sasaki, A.; Kanezashi, M.; Yoshioka, T. Pervaporation of methanol/dimethyl carbonate using SiO 2 membranes with nano-tuned pore sizes and surface chemistry. AIChE J. 2011, 57, 2079-2089. [CrossRef]

46. Huang, K.; Liu, G.; Lou, Y.; Dong, Z.; Shen, J.; Jin, W. A graphene oxide membrane with highly selective molecular separation of aqueous organic solution. Angew. Chem. Int. Ed. 2014, 53, 6929-6932. [CrossRef]

47. Dong, E.; Lin, Y. Synthesis of an organophilic ZIF-71 membrane for pervaporation solvent separation. Chem. Commun. 2013, 49, 1196-1198. [CrossRef]

48. Kopec, R.; Meller, M.; Kujawski, W.; Kujawa, J. Polyamide-6 based pervaporation membranes for organic-organic separation. Sep. Purif. Technol. 2013, 110, 63-73. [CrossRef]

49. Chen, J.H.; Liu, Q.L.; Zhu, A.M.; Zhang, Q.G.; Fang, J. Pervaporation separation of MeOH/DMC mixtures using STA/CS hybrid membranes. J. Membr. Sci. 2008, 315, 74-81. [CrossRef]

50. Chen, J.H.; Liu, Q.L.; Fang, J.; Zhu, A.M.; Zhang, Q.G. Composite hybrid membrane of chitosan-Silica in pervaporation separation of MeOH/DMC mixtures. J. Colloid Interface Sci. 2007, 316, 580-588. [CrossRef]

51. Liu, B.; Cao, Y.; Wang, T.; Yuan, Q. Preparation of novel ZSM-5 zeolite-filled chitosan membranes for pervaporation separation of dimethyl carbonate/methanol mixtures. J. Appl. Polym. Sci. 2007, 106, $2117-2125$. [CrossRef]

52. Wang, L.; Han, X.; Li, J.; Zhan, X.; Chen, J. Separation of azeotropic dimethylcarbonate/methanol mixtures by pervaporation: Sorption and diffusion behaviors in the pure and nano silica filled PDMS membranes separation of azeotropic dimethylcarbonate/methanol mixtures by pervaporation: Sorption. Sep. Sci. Technol. 2011, 46, 1396-1405. [CrossRef]

53. Wang, L.; Han, X.; Li, J.; Zhan, X.; Chen, J. Hydrophobic nano-silica/polydimethylsiloxane membrane for dimethylcarbonate-Methanol separation via pervaporation. Chem. Eng. J. 2011, 171, 1035-1044. [CrossRef]

54. Wang, L.; Han, X.; Li, J.; Qin, L.; Zheng, D. Preparation of modified mesoporous MCM-41 silica spheres and its application in pervaporation. Powder Technol. 2012, 231, 63-69. [CrossRef]

55. Zhou, H.; Lv, L.; Liu, G.; Jin, W.; Xing, W. PDMS/PVDF composite pervaporation membrane for the separation of dimethyl carbonate from a methanol solution. J. Membr. Sci. 2014, 471, 47-55. [CrossRef]

56. Vandezande, P.; Gevers, L.E.M.; Vankelecom, I.F.J. Solvent resistant nanofiltration: Separating on a molecular level. Chem. Soc. Rev. 2008, 37, 365-405. [CrossRef]

57. Homaeigohar, S.; Elbahri, M. Graphene membranes for water desalination. NPG Asia Mater. 2017, 9, e427. [CrossRef]

58. Nair, R.R.; Wu, H.A.; Jayaram, P.N.; Grigorieva, I.V.; Geim, A.K. Supporting online material for unimpeded permeation of water through helium-leak-tight graphene-based membranes. Science 2012, 335, 442-444. [CrossRef]

59. Huang, K.; Liu, G.; Jin, W. Vapor transport in graphene oxide laminates and their application in pervaporation. Curr. Opin. Chem. Eng. 2017, 16, 56-64. [CrossRef]

60. Castro-Muñoz, R.; Fíla, V.; Dung, C.T. Mixed matrix membranes based on PIMs for gas permeation: Principles, synthesis, and current status. Chem. Eng. Commun. 2017, 204, 295-309. [CrossRef]

61. Seoane, B.; Coronas, J.; Gascon, I.; Benavides, M.E.; Karvan, O.; Caro, J.; Kapteijn, F.; Gascon, J. Metal-organic framework based mixed matrix membranes: A solution for highly efficient $\mathrm{CO}_{2}$ capture? Chem. Soc. Rev. 2015, 44, 2421-2454. [CrossRef]

62. Ong, Y.K.; Shi, G.M.; Le, N.L.; Tang, Y.P.; Zuo, J.; Nunes, S.P.; Chung, T.S. Recent membrane development for pervaporation processes. Prog. Polym. Sci. 2016, 57, 1-31. [CrossRef]

63. Castro-Muñoz, R.; Galiano, F.; Fíla, V.; Drioli, E.; Figoli, A. Mixed matrix membranes (MMMs) for ethanol purification through pervaporation: Current state of the art. Rev. Chem. Eng. 2018. [CrossRef] 
64. Takht Ravanchi, M.; Kaghazchi, T.; Kargari, A. Application of membrane separation processes in petrochemical industry: A review. Desalination 2009, 235, 199-244. [CrossRef]

65. Castro-Muñoz, R.; Fíla, V. Progress on incorporating zeolites in matrimid ${ }^{\circledR} 5218$ mixed matrix membranes towards gas separation. Membranes (Basel) 2018, 8, 30. [CrossRef] 